\title{
REVIEW
}

\section{COLORECTAL CANCER SCREENING}

Frederico Ferreira Novaes de Almeida, Sérgio Eduardo Alonso Araujo, Fábio Pires de Souza Santos, Cláudio José Castro da Silva Franco, Vinicius Rocha Santos, Sergio Carlos Nahas and Angelita Habr-Gama

ALMEIDA FFN et al. — Colorectal cancer screening. Rev. Hosp. Clín. Fac. Med. S. Paulo 55 (1):35-42, 2000.

SUMMARY: Colorectal cancer (CRC) is the third most common cancer in the world, and mortality has remained the same for the past 50 years, despite advances in diagnosis and treatment. Because significant numbers of patients present with advanced or incurable stages, patients with premalignant lesions (adenomatous polyps) that occur as result of genetic inheritance or age should be screened, and patients with long-standing inflammatory bowel disease should undergo surveillance. There are different risk groups for CRC, as well as different screening strategies. It remains to be determined which screening protocol is the most cost-effective for each risk catagory. The objective of screening is to reduce morbidity and mortality in a target population. The purpose of this review is to analyze the results of the published CRC screening studies, with regard to the measured reduction of morbidity and mortality, due to CRC in the studied populations, following various screening procedures. The main screening techniques, used in combination or alone, include fecal occult blood tests, flexible sigmoidoscopy, and colonoscopy. Evidence from the published literature on screening methods for specific risk groups is scanty and frequently does not arise from controlled studies. Nevertheless, data from these studies, combined with recent advances in molecular genetics, certainly lead the way to greater efficacy and lower cost of CRC screening.

DESCRIPTORS: Colorectal cancer. Screening. Sigmoidoscopy. Colonoscopy. Fecal occult blood testing.

Colorectal cancer (CRC) is the third most common malignancy in the U.S. ${ }^{1}$ and is the second most important cause of cancer-related mortality ${ }^{2}$. Nearly 20000 CRC cases were newly diagnosed in Brazil in 1998, and an estimated 6000 Brazilians would have died of the disease by the end of that year ${ }^{3}$. The overall five-year mortality rate remains $50 \%$, unchanged over the last few decades (Fig. 1). Recent advances in operative techniques and adjuvant treatment have resulted in modest or no impact for patients with advanced disease $e^{4,5}$.

By the time symptoms of CRC occur, the majority of patients are found to have advanced disease. Considering the large numbers of people affected, and based on the consistent findings of lack of regression of cancer-related mortality - e.g. 60000 annual deaths in the U.S. ${ }^{6}$ - several investigators have concluded that development and improvement of CRC screening methods should become a top priority in order to reduce specific mortality. Consequently, over the past few years, special attention has been given to the modalities of CRC screening and their application in normal and elevated risk populations-including evaluations of their use alone as well as in combination. In view of the importance of these evaluations for determining the efficacy of CRC screening strategies, it is imperative that screening programs be carried out correctly.

From the Department of Gastroenterology, Hospital das Clínicas, Faculty of Medicine, University of São Paulo.

\section{DEFINITIONS}

Screening is the program for effective use of relatively simple and inexpensive tests in a large population of asymptomatic individuals, in order to identify those with elevated risk of cancer or a premalignant lesion. Only individuals testing positive in the screening test will then, undergo the more expensive and complex diagnostic work-up ${ }^{7}$. It must be clarified that the main objective of these tests is not diagnosis or evaluation of the progression of the disease, although these findings definitely occur. Rather, the main purpose of screening techniques is to reduce specific mortality of the studied population; therefore, if reduction in specific mortality cannot be measured, the benefit related to the 
method cannot be demonstrated. Any benefit associated with a screening program must be ideally compared to an unscreened population-a control group. At the end of the study, if better cancer-related survival is obtained, a cost-effectiveness evaluation must be performed.

There is little doubt that earlier diagnosis of CRC will result in better survival. Patients with stage I lesions ${ }^{8}$ (TNM classification -American Joint Committee on Cancer-AJCC/Union Internationale Contre Cancer-UICC) exhibit a $90 \%$ five-year survival rate, whereas mean survival rates after five years of patients with stage IV disease is $10 \%$.

Elevated lesions of the large bowel mucosa are generally called polipoyd lesions or polyps and can exhibit several histologic characteristics. ${ }^{9}$ It is well established that most cases of CRC originate from adenomatous polyps in a relatively well known process that develops over several years ${ }^{10}$ (Fig. 2). This characteristic of CRC provides the opportunity for detection and prevention of disease progression through endoscopic recognition and excision of adenomatous polyps, malignant polyps, and some early cancers.

A significant segment of the population has an elevated risk of developing CRC due to genetic predisposition. These individuals may benefit from screening early in their lives by different methods than those designed for the general population. Surveillance is the term more commonly used to define screening methods for patients with more than average risk for CRC.

Principles of CRC screening - The following principles for screening programs are recommended by the World Health organization (WHO $)^{11}$ :

1) The disease under investigation should represent a major health problem leading to substantial morbidity and mortality;

2) The natural history of the disease

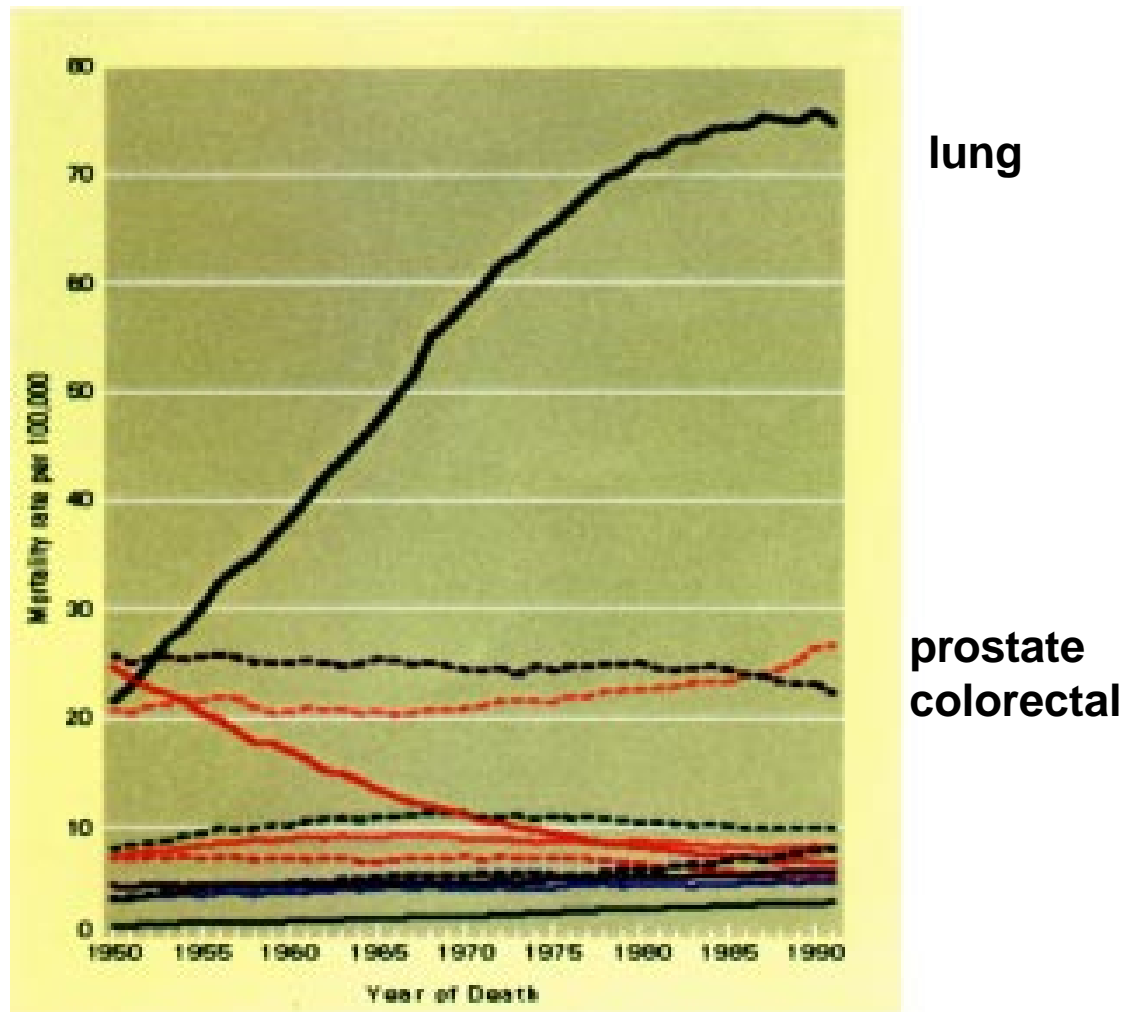

Figure 1 - Colorectal cancer: evolutive mortality. Source: National Cancer Institute (NCI) Public Use Files (USA).

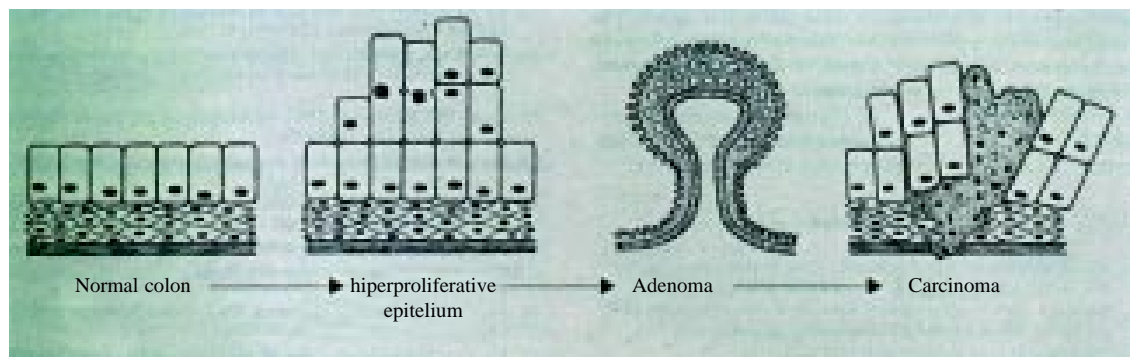

Figure 2 - Adenoma-carcinoma sequence.

should be known at large, and the detection of premalignant or asymptomatic phases should be possible by preexisting methods. Readily available, full diagnostic investigation should be provided for individuals with positive screen tests;

3) Methods should be sensitive and safe, and their application should reduce disease incidence;
4) A target population must be previously defined;

5) Screening costs should be considered part of preventive efforts.

\section{METHODS}

Fecal occult blood testing (FOBT) - The rationale for CRC detection by using FOBT is that neoplas- 
tic lesions bleed more than the normal intestinal mucosa. The amount of blood detected increases with the size of the lesion as well the stage of the tumor. FOBT provides an indirect sign of the presence of lesions, which may not be neoplastic and also may not be located in the large bowel. Furthermore, bleeding from neoplasms may be intermittent. Therefore, patients with a positive test must undergo diagnostic evaluation through double contrast enema or colonoscopy ${ }^{9}$.

A study conducted in Denmark in 1985 involved approximately 65000 individuals aged between 45 and 74 years who underwent FOBT twice within an interval of 2 years. A sensitivity rate of $52 \%$ was obtained, and results after a ten-year follow-up period indicated that a $52 \%$ reduction in mortality was achieved ${ }^{13}$. In Brazil, Habr-Gama et al. ${ }^{7}$ conducted a multicenter FOBT study that comprised 3000 individuals. Diagnostic evaluations were performed on more than $70 \%$ of FOBT positive participants who voluntarily participated. Of the 88 patients with a positive test who underwent the complete diagnostic evaluation, ten cases of CRC were diagnosed, corresponding to a $11.3 \%$ risk of cancer among patients with positive test ${ }^{7}$.

These results seem to confirm the widely accepted notions about the efficacy of FOBT for CRC screening. Although FOBT represents a relatively simple and therefore acceptable procedure, its lack of sensitivity may compromise wide application. Similarly, its relatively low specificity may result in a high operational cost due to the need for colonoscopy to rule out cancer in patients with false-positive tests.

Flexible sigmoidoscopy - Flexible sigmoidoscopy using a 60-cm instrument will detect polyps of varying histology and neoplastic potential in up to $23-38 \%$ of patients screened. As a screening tool, sigmoidoscopy has the following advantages when compared to FOBT: 1) allows direct visualization of colorectal mucosa (Fig. 3); 2) detected lesions can be biopsed or excised during the exam; 3) it has a high sensitivity and specificity for polyps in the examined segments ${ }^{9}$. The main disadvantage of sigmoidoscopy is that only the left colon is within the reach of the scope; therefore, colonoscopy is indicated for patients with diagnosis of polypoid lesions or cancer at sigmoidoscopy.
There are no data from prospective randomized trials designed to evaluate the role of sigmoidoscopy in CRC screening. Nevertheless, evidence from case-control studies indicate that sigmoidoscopy screening can reduce CRC-specific mortality. Selby et $\mathrm{al}^{14}$ identified a reduction of $59 \%$ in mortality for CRC diagnosed in colon segments within the reach of sigmoidoscopy.

Although recent reviews have demonstrated that screening with sigmoidoscopy leads to the discovery of early curable cancers and premalignant polyps that can be removed (and consequently to a $70-79 \%$ reduction in occurrence of fatal CRC in the distal colon), sensitivity, specificity, and predictive values for sigmoidoscopy are yet to be defined.

Colonoscopy - Visualization of the entire colon by colonoscopy obviously remains the gold standard for detecting and removing colonic neoplasms, and colonoscopy has the potential to extend the benefit offered by sigmoidoscopy. However, full mechanical preparation of the colon and conscious sedation are required for adequate examination. During colonoscopy, air insufflation of the bowel loops is necessary for care-
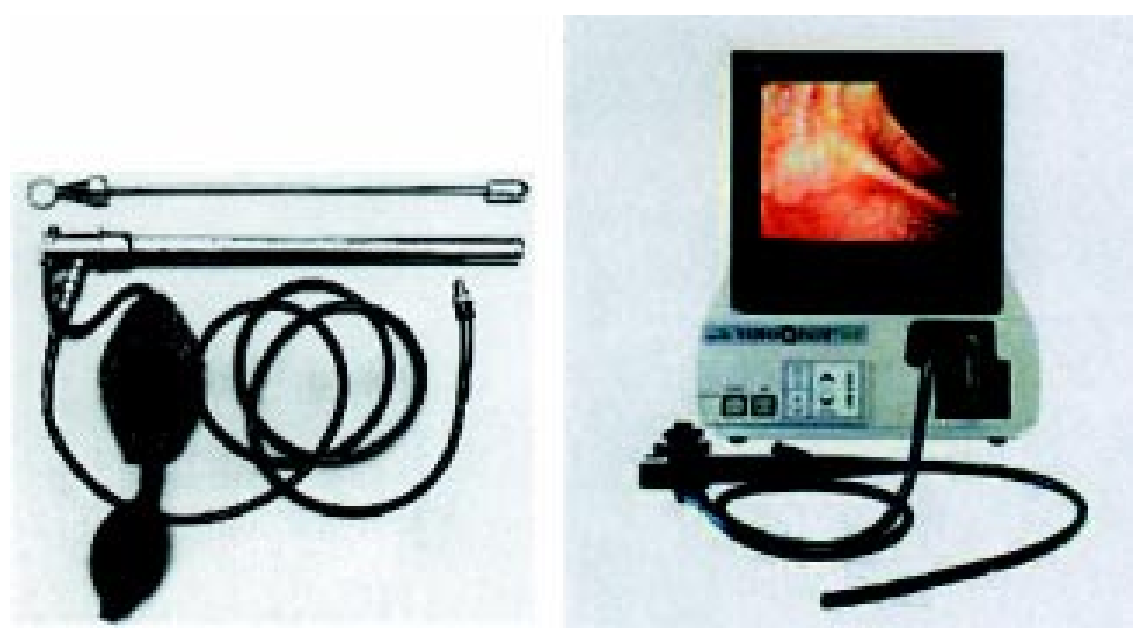

Figure 3 - Rigid and flexible sigmoidoscopes. 

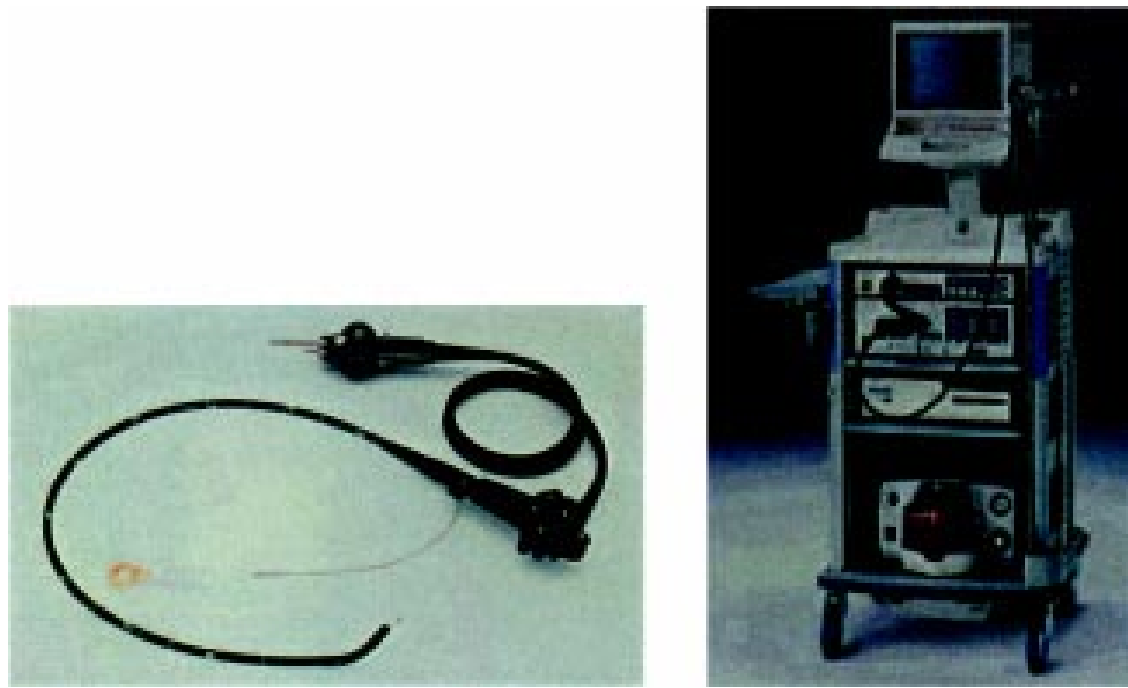

Figure 4 - Videocolonoscope. Insertion tube (left) and complete set (right): insertion tube, monitor, light source, and image processor.

ful observation and examination, and insufflation rarely lasts more than ten minutes. In comparison to FOBT, which has a low sensitivity for detection of small lesions, and to sigmoidoscopy, which permits only distal colon observation, colonoscopy is the superior method. Furthermore, colonoscopy provides prompt removal of premalignant lesions throughout the colorectum. Colonoscopy provides a high degree of sensitivity to a screening protocol but also adds considerably to the overall costs. Data suggest that the initial colonoscopy may be the most important factor in reducing the risk of subsequent cancer: after colonoscopy, the patient may not be at a greater risk than the normal population within the same age group ${ }^{15}$.

Definition of risk groups for CRC As a consequence of better knowledge about the development of CRC and of data from population and molecular genetic studies, there is a better understanding and more accuracy when considering the risk of CRC for a given individual.

Nearly $75 \%$ of the normal population are considered to be in a so-called "normal risk" group for CRC. The re- maining $25 \%$ individuals belong to the "elevated risk" group. They include:

1. patients with inflammatory bowel disease (ulcerative colitis and Crohn's disease) $-1 \%$;

2. individuals with diagnosis of familial adenomatous polyposis (FAP) $-1 \%$;

3. patients with diagnosis of hereditary nonpolyposis colorectal cancer (HNPCC) $-5 \%$.

4. individuals with a family history of CRC in a first degree relative, but without any known inherited genetic defect-15 to $25 \%{ }^{15}$.

Some historical case-control studies have found that there is a two to four times increased risk of CRC when there is a family history of CRC, al- though the issue is still controversial $^{16,17}$. Consequently, for a single individual, it is important to scrutinize the family history to determine whether it fulfills Amsterdam's criteria for HNPCC $^{18}$ (Table 1). For the group of individuals from families suspected of harboring HNPCC, the screening modality must be different from the protocol that would be used for patients with a positive family history of only one first degree relative, for example. Genetic testing for HNPCC is currently limited to research facilities and is not yet generally available.

CRC screening strategies Screening the entire adult population by colonoscopy is clearly not currently feasible, so better ways of defining subgroups that are at risk have become

Table 1 - Amsterdam's criteria to the diagnosis of family history of hereditary nonpolyposis colorectal cancer (HNPCC).

1. Identification of three or more relatives with $\mathrm{CRC}$, and

2. Two of whom are first-degree relatives of the third;

3. At least two generations are involved;

4. One person diagnosed with CRC before age 50 . 
necessary in order to make optimal use of the available resources. Although the potential exists to achieve a better survival rate through the use of one screening modality or the use of two or more modalities in combination, the feasibility, availability of technology, costs, and adherence to protocol of both medical personnel and patient must be evaluated.

As result of prospective randomized as well as case-control studies ${ }^{9,15}$, some strategies of CRC screening were published in 1997 and adopted by the American Cancer Society, American College of Gastroenterology and American Society of Colon and Rectal Surgeons. These strategies are based on the following principles:

1. individuals with symptoms or signs of CRC qualify for an appropriate diagnostic work-up, and they are not candidates for screening methods;

2. individual or family risk of CRC must be scrutinized on the basis of the current knowledge of hereditary $\mathrm{CRC}$, and these risks must be determined before screening starts;

3. CRC and polyp screening must be offered to the average male and female population at the age of 50;

4. diagnostic work-up must follow positive screening tests;

5. inflammatory bowel disease and personal history of CRC indicate the need for surveillance by different methods;

6. screening strategies must include efforts to increase patients' and health professionals' adherence;

7. adequate information to the population about risks and benefits associated with CRC screening methods must be provided, and full understanding must be assured.

People at average risk (everyone at age 50) - For these individuals, an annual FOBT or flexible sigmoidos- copy at five-year intervals is recommended for screening — either by one or both methods.

Approximately $70-80 \%$ of all CRC occur among people at average risk. Average risk is defined by default as anyone who is not otherwise defined as being at elevated risk as defined below.

The role of sigmoidoscopy in reducing CRC-associated mortality is based on evidence provided by casecontrol studies ${ }^{14,19,20}$. The disadvantages associated with this strategy are the impossibility of total colon evaluation with sigmoidoscopy and the discomfort of the exam to the patients. Although the combination of FOBT and sigmoidoscopy is recommended as an alternative screening protocol, there is little or no evidence of benefit associated with this strategy .

People at elevated risk - Family history of familial adenomatous polyposis (FAP).

Individuals with family history of FAP must receive genetic counseling and consider genetic tests to detect the presence of APC (adenomatous polyposis coli) gene germline mutation. For an individual with a family history of FAP, a negative test for this mutation rules out inheritance of the mutant gene. For individuals with positive or indeterminate tests, flexible sigmoidoscopy at 12-month intervals must be offered starting before puberty with the objective of identifying gene expression through the phenotype of multiple colon adenomatous polyps. Individuals with FAP develop hundreds to thousands of colonic adenomas that will become cancerous unless the colon is surgically removed.

Family history of hereditary nonpolyposis colorectal cancer (HNPCC) - People with a family history of CRC in three or more family members, two of whom are first-degree relatives of the third, involving people in at least two generations, and with one person diag- nosed with CRC before age of 50 years (Table 1) must receive genetic counseling and consider genetic testing for HNPCC. For these individuals at elevated risk, total colon evaluation through colonoscopy must be offered every one or two years starting between ages 20 and 30 and annually after 40 years of age. HNPCC cancers do not usually arise from polyps, are frequently multiple, occur at young age, and are proximal to the splenic flexure ${ }^{21}$.

Individuals with inflammatory bowel disease - For patients with longstanding ulcerative colitis, colonoscopy should be offered annually after eight years from the start of pancolitis and after 13 to 15 years from the start of left-sided colitis until colectomy. However, no demonstrated benefit has yet been associated with this strategy ${ }^{9}$.

Individuals with family history of CRC or adenomatous polyp - For these individuals, the average risk population strategy (see 6.1) must be offered starting at the age 40 . Whether patients with a family history of CRC or adenomatous polyps (not associated with HNPCC or FAP) are at increased risk of developing CRC has not yet been convincingly demonstrated and remains controversial.

Personal history of adenomatous polyp excision - After endoscopic removal of one or more adenomatous colonic polyps, the first surveillance colonoscopy must follow after a threeyear interval. After a negative result, the next exam must be made after five years.

Personal history of curative-intent resection of CRC - The objective of follow-up after resection of CRC is to detect recurrences, synchronic cancers, and metachronic cancers or adenomas. After a complete preoperative colonoscopy during the diagnostic phase of a CRC, total colon evaluation must follow after a three-year interval, and if negative, after five years ${ }^{9}$. 


\section{CONCLUSIONS}

There is reasonable evidence to indicate that individuals experience benefits from the early detection of CRC and polyps as result of the application of these screening methods. Follow-up results from the few available prospective randomized trials indicate that there is a better survival rate associated with the screened groups compared to unscreened groups ${ }^{9}, 15$.

Although we do not yet have enough data to compare the various methods for screening, some of the specific mortality associated with CRC can be prevented by screening. The best association between a specific risk group and the most efficient method remains to be determined. The three main methods used for CRC screening are: FOBT, flexible sigmoidoscopy, and colonoscopy—used individually or in combination.

Although it is inexpensive and easily done, FOBT suffers from low sensitvity and specificity. Cancer detection rates by this method are lower than the estimated rates for a considered population based on colonoscopy data.
Screening colonoscopy is best indicated in elevated risk group individuals, such ulcerative colitis patients or individuals from HNPCC suspected families $^{9,21}$, although the true efficacy of this approach is still to be demonstrated. There are no reliable data about the best intervals between screening examinations for the elevated risk group of individuals. For patients with family history of CRC not related to HNPCC, better definition of subgroups is expected from genetic studies about gene mutation types and its prevalence in sporadic CRC. It is expected that these data may result in cost reduction and better effectiveness of screening for these high risk kindividuals.

Case-control and descriptive studies provided the best evidence about better survival with sigmoidoscopybased screening protocols ${ }^{14,25,26}$. Although sigmoidoscopy cannot provide a full colon examination, the low sensitivity associated with FOBT and the high cost and low adherence to protocol associated with colonoscopy have led to a growing choice of sigmoidoscopy as an attractive screening tool for average risk group individuals.
The main barriers to research and development in the field of CRC screening methods and strategies include:

- the complexity associated with the planning of large prospective randomized trials including average and specific risk populations;

- the necessity to measure the effectiveness and costs associated with the application of a specific screening tool; and

- controversies about definitions of average and elevated risk groups.

Attempting to establish what must occupy the mind of physicians when screening any one individual, we understand that there is a need for a more sensitive test than FOBT, a less invasive and less expensive method than colonoscopy, and a more comprehensive examination than sigmoidoscopy.

The high prevalence and significant morbidity and mortality resulting from CRC throughout the world and in Brazil as mentioned above, associated with the unequivocal benefit associated with the early detection of CRC may lead to the consideration of CRC screening as a high priority research issue within public health affairs.
ALMEIDA FFN e col. - Rastreamento do câncer colorretal. Rev. Hosp. Clín. Fac. Med. S. Paulo 55 (1):35-42, 2000.

O câncer colorretal (CCR) é a terceira neoplasia mais freqüente no mundo. A mortalidade persiste inalterada nos últimos 50 anos a despeito dos avanços obtidos em diagnóstico e tratamento. Significativa parcela dos do- entes se apresenta com tumores em estágio avançado ou incuráveis de onde se depreende a necessidade de rastreamento dos pacientes com lesões pré-malignas (pólipos adenomatosos) como resultado de herança genética ou idade, e de vigilância dos portadores de doença inflamatória intestinal de longa evolução. Na medida em que existem diferentes grupos de risco identificáveis para CCR e diferentes estra- tégias para o rastreamento, há que se determinar o protocolo de triagem capaz de oferecer maior relação custo-benefício. Uma vez que o objetivo das técnicas de rastreamento é diminuir a morbi-mortalidade da população analisada, o presente trabalho objetiva conhecer, sob essa perspectiva, os resultados dos estudos disponíveis até o momento para o rastreamento do CCR. Os principais métodos de rastreamento 
incluem, isoladamente ou em associação, o emprego da pesquisa de sangue oculto nas fezes, a sigmoidoscopia e o exame colonoscópico. As evidências de literatura a respeito dos métodos de rastreamento para os diversos grupos de risco específicos são insuficientes e, freqüientemente, não envolvem estudos controlados. A necessidade de realização desses estudos associada ao progresso nos estudos de genética molecular resultará em maior eficácia e menor custo associados ao rastreamento do CCR.

DESCRITORES: Câncer colorretal. Rastreamento. Sigmoidoscopia. Colonoscopia. Pesquisa de sangue oculto nas fezes.

\section{REFERENCES}

1. SHIKE W, WINAWER SJ, GREENWALD PH et al. - Primary prevention of colorectal cancer: the WHO Collaborating Centre for the Prevention of Colorectal Cancer. Bull World Health Organ 1990; 68: 377-385.

2. LANDIS SH, MURRAY T \& BOLDEN S - Cancer statistics 1998. CA Cancer J Clin 1998; 48: 6-29.

3. MINISTÉRIO da Saúde - Instituto Nacional do Câncer/PRO-ONCO. - Estimativa da Incidência e Mortalidade por Câncer no Brasil. Rio de Janeiro, 1998.

4. KROOK JE, MOERTEL CG, GUNDERSON LL et al. - Effective surgical adjuvant therapy for high-risk rectal carcinoma. N Engl J Med 1991; 324: 709-715.

5. MOERTEL CG, FLEMING TR, MACDONALD JS et al. - Levamisole and fluorouracil for adjuvant therapy of resected colon carcinoma. N Engl J Med 1990; 322: 352-358.

6. WINAWER SJ, FLEISHER M, BALDWIN M et al. - Current status of fecal occult blood testing in screening foe colorectal cancer. CA Cancer J Clin 1982; 32: 100-112.

7. HABR-GAMA A, MOREIRA H, FREITAS IM et al. - Rastreamento do câncer colorretal pela prova do guaiaco modificada: estudo multicêntrico no Brasil. Rev Gastroent Endosc Dig 1983; 2: 30-36.

8. HUTLER RVP \& SOBIN LH - A universal staging system for cancer of the colon and rectum. Let there be light. Arch Pathol Lab Med 1986; 110: 367-368.

9. WINAWER SJ, FLETCHER RH, MILLER L et al. - Colorectal Cancer Screening: Clinical Guidelines and Rationàle. Gastroenterology 1997; 112: 594-642.

10. MORSON BC - Polyp-cancer sequence of the large bowel. Proc Roy Soc Med 1974; 67: 461.

11. CANADIAN Task Force on the Periodic Health Examination - The periodic health examination II. Can Med Ass J 1979; 121: 11931254.
12. KHULLAR SK \& DISARIO JA - Colon Cancer Screening. Sigmoidoscopy or Colonoscopy. Gastrointest Endosc Clin North Am 1997; 7(3): 365-383.

13. KRONBORG O, FENGER C, OLSEN J et al. - Randomised study of screening for colorectal cancer with faecal occult blood test. Lancet 1996; 348: 1467-1471.

14. SELBY JV, FRIEDMAN GD, QUESENBERRY CP et al. - A casecontrol study of screening sigmoidoscopy and mortality from colorectal cancer. N Engl J Med 1992; 326: 653-657.

15. MARKOWITZ AJ \& WINAWER SJ - Screening and surveillance for colorectal carcinoma. Hematol Oncol Clin North Am 1997; 11(4): 579-608.

16. BONELLIL, MARTINES H, CONIO Met al. - Family history of colorectal cancer as a risk factor of benign and malignant tumours of the large bowel. A case-control study. Int J Cancer 1988; 41: 513-517.

17. PONZ DE LEON M, ANTONIOLI A, ASCARI A et al. - Incidence and familial occurrence of colorectal cancer and polyps in a healthcare district of Northern Italy. Cancer 1987; 60: 2848-2859.

18. VASEN HFA, MECKLIN JP, KAHN PM et al. - The international Collaborative Group on Hereditary Non-Polyposis Colon Cancer (ICG-HNPCC). Dis Colon Rectum 1991; 34: 424-425.

19. MULLER AD \& SONNENBERG A - Protection by endoscopy against death for colorectal cancer. Arch Intern Med 1995; 155: 1741-1748.

20. NEWCOMB PA, NORFLEET RG, STORER BE et al. - Screening sigmoidoscopy and colorectal cancer mortality. J Natl Cancer Inst 1992; 84: 1572-1575.

21. BOND JH - Colorectal surveillance for neoplasia: an overview. Gastrointest Endosc 1999; 49: S35-40.

22. LOVE RR \& MORRYSSEY JF - Colonoscopy in asymptomatic individuals with a family history of colorectal cancer. Arch Inter Med 1984; 144: 2209-2211. 
23. LENNARD-JONES JE, MELVILLE DM, MORSON BC et al. Precancer and cancer in extensive ulcerative colitis. Findings among 401 patients over 22 years. Gut 1990; 31: 800-806.

24. TURUNEN MJ \& JARVINEN HJ - Cancer in ulcerative colitis. What failed in follow-up? Acta Chir Scand 1985; 151: 669-673.
25. GILBERTSEN VA - Proctosigmoidoscopy and polipectomy in reducing the incidence of colorectal cancer. Cancer 1974; 34: 936-939.

26. HERTZ REL, DEDDISH MR \& DAY E - Value of periodic examinations in detecting cancer of the colon and rectum. Postgrad Med 1960; 27: 290-294.

Received for publication on the: 20/02/00 